This document is the accepted manuscript version of the following article:

Vitasse, Y., \& Rebetez, M. (2018). Unprecedented risk of spring frost damage in Switzerland and Germany in 2017. Climatic Change, 149(2), 233-246.

https://doi .org/10.1007/s10584-018-2234-y

\title{
Unprecedented risk of spring frost damage in Switzerland and Germany
} in 2017

Yann Vitasse ${ }^{* 1,2}$ and Martine Rebetez ${ }^{1,3}$

${ }^{1}$ University of Neuchatel, Institute of Geography, Neuchatel, Switzerland

${ }^{2}$ WSL Swiss Federal Institute for Forest, Snow and Landscape Research,

Birmensdorf, Switzerland

${ }^{3}$ WSL Swiss Federal Institute for Forest, Snow and Landscape Research, Neuchatel, Switzerland

*Corresponding author. Tel: +41(0)32 718 1637, e-mail: yann.vitasse@wsl.ch, ORCID: 0000-0002-7454-505X, address: Institute of Geography, Espace LouisAgassiz 1, 2000 Neuchatel, Switzerland

\begin{abstract}
Spring frosts are feared by farmers, fruit- and wine growers as they can cause significant damage to crops when they occur during the development of the plants. In the second half of April 2017, following a very warm period that had caused premature vegetation growth, a cold air mass from the Arctic penetrated central and western Europe, causing severe damage to natural and cultivated vegetation over broad areas. Here we analyze how exceptional this event was in Switzerland and Germany in relation to the accumulated growing degree days (GDD), used as a proxy for plant phenology advancement. Although this damaging frost was not the latest on record in terms of calendar days, our results show that it was, in some regions, unprecedented in relation to the accumulated warmth during the preceding period, at least since the beginning of instrumental temperature records (1864). Our results also highlight how global warming has considerably increased the number of days with mean temperature above $5^{\circ} \mathrm{C}$ in late winter and early spring, especially since 1970 $\left(+16.8 \pm 4.7^{\circ} \mathrm{C}\right.$.days.decade $\left.{ }^{-1}\right)$. However, in spite of earlier spring phenology due to climate warming, our results suggest that the risk of damaging frost events to vegetation has remained unchanged over the last 150 years in lowlands of Switzerland and Germany, due to the concurring earlier occurrence of the last potentially damaging frosts (about -20 days since 1864). Our analyses reveal therefore that the April 2017 damaging frost was a true outlier in terms of risk of frost damage to plants.
\end{abstract}

Keywords: agriculture, frost damage, growing degree days, perennial plants, spring frost, climate warming.

\section{Acknowledgements}

Long-term series of temperature data and the Spring phenological index data were provided by MeteoSwiss, the Swiss Federal Office of Meteorology and Climatology (https://gate.meteoswiss.ch/idaweb, access upon request). We thank Flurin Sutter for his support in drawing the map of the selected stations shown in Fig. 2. We are 
grateful to Regula Gehrig from MeteoSwiss for providing the data of the Swiss spring phenology index. We are grateful to John Innes for his useful comments and suggestions. The research leading to these results was funded by the Swiss Federal Office for the Environment (FOEN, grant number 09.0064.PJ / P453-1685 and A200.0001). 


\section{Introduction}

During the $20^{\text {th }}$ Century, minimum temperatures were generally observed to increase more than maximum temperatures in the Northern hemisphere (Easterling et al., 1997; Hansen et al., 1995; Karl et al., 1993), including Switzerland (Rebetez, 2001). However, during the recent decades, maximum temperatures have been increasing more than minimum temperatures in central and western Europe (Matiu et al., 2016; Rebetez and Reinhard, 2008; Vitasse et al., 2018a), with the mean rise in maximum temperatures approximately twice that of minimum temperatures. Such warming implies that young leaves of perennial temperate plants could be more exposed to frost events as bud react more to daytime temperatures than to night-time temperatures during their ecodormancy phase (Fu et al., 2016), whereas late frosts are determined by minimum temperatures. The overall frequency of frosts has decreased with global warming in temperate latitudes and is expected to decrease further in the coming decades (IPCC, 2013). The date of the last spring frost has been shifting earlier in Europe (Scheifinger et al., 2003), on average by about 2.6 days.decade $^{-1}$ in the lowlands of Switzerland during the period 1975-2016 (Vitasse et al., 2018a). However, vegetation onset in spring has also been advancing with climate warming, typically by almost two weeks during the period 1982-2011 in western Europe (Fu et al., 2014) but not necessarily at the same pace as late frost events, thus possibly changing the risk of frost injury to plants (Augspurger, 2013; Hänninen, 1991; Rigby and Porporato, 2008).

Perennial plants from temperate latitudes have evolved to adjust their growth in relation to seasonal temperature variation, in particular to avoid vulnerable tissues such as young leaves, flowers or dehardened buds being exposed to freezing temperatures (Vitasse et al., 2014). Thus, the beginning of spring growth often coincides with the mean long-term probability of frost risk in a given region so that perennial plants are only rarely injured by frosts (Lenz et al., 2016). This synchronization results from a complex response of the plants to environmental cues such as chilling duration in winter, responsible for dormancy release (Coville, 1920), and increasing photoperiod and warmer temperatures in spring, promoting bud break (reviewed in Delpierre et al., 2016). Current and future global warming may potentially disrupt this complex synchrony for natural vegetation. Besides, humans have heavily modified the genetics of crops to increase yield (Gepts, 2006) and have sometimes planted varieties far away from their geographical origin, so that their phenology may no longer be adapted to the risk of frost injury. However, the destruction of flowers or young fruits by frost may cause considerable economic loss for fruit and vine growers as it can dramatically reduce the production (Rodrigo, 2000). This may occur when a cold air mass dominates after a significant warm period in early spring that promotes premature vegetation development, also called a 'false spring' (Marino et al., 2011).

Several recent damaging spring frost events have been reported as causing severe damage over broad areas after an early vegetation start. Examples include the USA in 2007 (Augspurger, 2009; Gu et al., 2008), 2010 (Hufkens et al., 2012) and 2012 
(Kistner et al., 2018), France in 1995 (Ningre and Colin, 2007), and Switzerland, south Germany and northeastern France in 2011 and 2016 (Kreyling et al., 2012; Vitasse et al., 2018a; personal observations 2016). Although these damaging frosts did not occur exceptionally late in terms of calendar days, they all followed an unusually warm period causing earlier than normal plant development. They all caused important economic losses. For instance, the spring frost that occurred in April 2007 in south-central and southeastern USA caused agricultural losses estimated at about $€ 1.6$ billion (Marino et al., 2011).

Before the damaging frost event of April 2017 in Europe studied here, the beginning of April was very warm. The passage of a cold front penetrated central and western Europe on April $17^{\text {th }}$, followed by a large incursion of very dry polar air. Several clear nights followed, leading to temperatures down to below $-4^{\circ} \mathrm{C}$ in the lowlands of Switzerland and Germany from April $20^{\text {th }}$ to April $24^{\text {th }}$. Following an exceptionally warm period promoting premature vegetation growth, this frost, led to severe frost damage to natural and cultivated vegetation, causing important economic losses to farmers, particularly in orchards and vineyards (Fig. 1). In Switzerland, the economic loss related to this frost event has been estimated to exceed $€ 80$ million for fruit crops alone and was locally described as the 'frost of the century' by the local media (https://www.thelocal.ch/20170512/swiss-cantons-look-to-help-farmers-after-frost-ofthe-century-wiped-out-crops). Munich Re later (January 2018) published an estimation of the economic loss of $€ 3.3$ billion for the whole European area (https://www.munichre.com/topics-online/en/2018/01/spring-frost).

Here, we analyze how exceptional the April 2017 damaging frost was in lowland regions in relation to the accumulated growing degree days (GDD), which we use as a proxy for spring phenology. We utilized long-term temperature records from Switzerland and Germany that extend back to 1864 . We also examined whether the accumulated GDD at the time of the last potentially damaging frost has changed over the last 154 years, indicating how the risk of frost injury to vegetation is changing, particularly during the last five decades that have been marked by pronounced warming

\section{Data and Methods}

\subsection{Selection of the study sites}

Time series of daily minimum and maximum temperatures from 51 stations in Switzerland and Germany were included in the analysis using the MeteoSwiss database (https://gate.meteoswiss.ch/idaweb). Three criteria were used in the station selection: 1) the station was located below $600 \mathrm{msl}$, 2) minimum temperatures fell below $-2^{\circ} \mathrm{C}$ during 20-29 April 2017 (last frost 2017 for all the study stations), and 3) the period of record exceeded 40 years. The first criterion was applied as plant phenology at elevations above $600 \mathrm{msl}$ was less advanced and less susceptible to frost damage during the April 2017 frost. The $-2^{\circ} \mathrm{C}$ criterion was selected because it is often considered as the threshold for a damaging hard freeze, especially on perennial vegetation (Marino et al., 2011; Snyder and Melo-Abreu, 2005). However, cold frost 
hardiness is highly dependent on the phenological stage of the plant, on the species/varieties and on the affected organs. For instance, the minimum freezing resistance of leaves is generally observed during leaf emergence (Lenz et al., 2013; Vitra et al., 2017) whereas fruits are most frost sensitive during their first phase of formation, shortly after flowering (Osaer et al., 1998). The third criterion ensured a sufficiently long record length for climatological comparisons among numerous stations, although earlier data (up to 1864 for the earliest) were also analyzed. Additional analyses were conducted for a subset of 16 stations that experienced temperatures below $-4^{\circ} \mathrm{C}$ during the 20-24 April 2017.

The selected stations covered elevations between $4 \mathrm{~m}$ and $588 \mathrm{~m}$ and latitudes between $46.3^{\circ} \mathrm{N}$ and $53.5^{\circ} \mathrm{N}$, with data starting from 1864 for the station Bern / Zollikofen, Switzerland (see map Fig. 2 and list of all the selected stations in Tables S1 \& S2 and Fig. S2 for the number of stations available per year). Some of the longest series from Switzerland were homogenized by MeteoSwiss ( 8 stations) to increase the quality for long-term trend analyses by using monthly homogeneity adjustments, and daily data were then derived by applying a spline function (Begert et al., 2005). These homogenized series were used in the analyses but similar patterns were found with non-homogenized temperature data. Climate data are available from the Swiss Federal Office of Meteorology and Climatology upon request (https://gate.meteoswiss.ch/idaweb).

\subsection{Analyses and statistics}

For all weather stations, daily mean temperature values were computed by averaging daily minimum and maximum temperature data. Accumulated growing degree days (GDD) in late winter and spring, is a widely-used proxy for phenology based on daily mean temperature values, intended to predict the time of spring phenology phases for natural and cultivated plant species (e.g. Sacks and Kucharik, 2011; Wang and Engel, 1998). We therefore calculated the number of GDD for every year/station as the sum of daily mean temperature above $5^{\circ} \mathrm{C}$ since January $1^{\text {st }}$ to the date of the last spring frost based on 2 thresholds $\left(\leq-2^{\circ} \mathrm{C}\right.$ and $\leq-4^{\circ} \mathrm{C}$ ) as well as for a fixed period from January $1^{\text {st }}$ to April $19^{\text {th }}$ (i.e. just before the late spring frost event of 2017) as follows: $G D D=\sum_{t_{0}}^{t_{1}}\left(T_{a}-5\right) I\left(T_{a} \geq 5\right)$

where GDD is the number of growing degree days for a given station and a given year, accumulated from $t_{0}$, January $1^{\text {st }}$, to $t_{1}$ which corresponds to the date of the last frost $\leq-2^{\circ} \mathrm{C}$ or $\leq-4^{\circ} \mathrm{C}$ (first computation), or to the fixed date of April $19^{\text {th }}$, i.e. the day before the late spring frost 2017 (second computation). $T_{a}$ is the daily mean temperature value and $I()$ is an indicator equal to 1 when its argument is true and 0 otherwise.

The first computation allowed us to compare the damaging frost 2017 conditions with all previous years since up to 1864 in terms of the risk of frost damage evaluated at the last frost event $\leq-2^{\circ} \mathrm{C}$ or $\leq-4^{\circ} \mathrm{C}$. The higher the GDD accumulated before the frost event, the higher the risk for plants to be injured by frost. The second computation enabled us to assess how warm the late winter and early spring of 2017 
had been in comparison to all previous years since 1864, irrespective of when the last frost had occurred.

In order to combine results of all stations, we computed for each station and available year the anomaly of the accumulated GDD before the last frost of the spring season $\leq-2^{\circ} \mathrm{C}$ or $\leq-4^{\circ} \mathrm{C}$ as the deviation from the mean of the given station during the period 1981-2010. Yearly anomalies of the last frost occurrences below both thresholds were calculated similarly. Kernel distributions of the GDD deviations or last frost date deviations were then plotted for all stations-years available, highlighting the April 2017 frost in red. For testing temporal trends in GDD deviations or in last frost deviations, linear regressions were applied and, when significant, slopes were reported.

In order to check the robustness of the GDD as a proxy for spring phenology, we correlated it to the Spring index computed by MeteoSwiss from 1951 to 2017 (http://www.meteoswiss.admin.ch/home/climate/climate-change-inswitzerland/vegetation-development/spring-index.html). This index represents the time of vegetation development in the spring compared to the 1981-2010 average from nearly 80 stations with sufficiently long data series of phenological observations and is therefore a good statistical indicator for the time of vegetation development throughout Switzerland.. The spring index includes the flowering dates of hazel (Corylus avellana L.), coltsfoot (Tussilago farfara L.), wood anemone (Anemone nemorosa L.), cherry tree (Prunus avium L.), common dandelion (Taraxacum officinale aggr.) and cuckooflower (Cardamine pratensis L.) as well as the leaf-out dates of horse chestnut (Aesculus hippocastanum L.), hasel, larch (Larix decidua L.) and beech (Fagus sylvatica L.).

All data analyses were performed using Rstudio version 0.99.489 (R Core Team, 2015)

\section{Results}

\subsection{The uniqueness of the April damaging frost 2017}

At the 16 locations in Switzerland and Germany where temperatures dropped below $-4^{\circ} \mathrm{C}$ on 20-24 April 2017 (Table S1), the GDD accumulation at the time of the last frost $\leq-4^{\circ} \mathrm{C}$ was in 2017 the highest on record for half of them, exceeding 160 GDD. These stations are located in Switzerland (Bern 202 GDD, Koppigen 193 GDD 283, Delémont GDD 213, Hallau GDD 195, Fig. 2), south Germany (Baden-Baden GDD 247, Wutoeschingen-Ofteringen GDD 203, Mühldorf GDD 160, Fig. 2) and western Germany (Düsseldorf, GDD 249, Fig. 2). For one station in northern Switzerland (Aadorf) and two in southern Germany (Weingarten, Sigmaringen), the GDD accumulation at the time of the last frost ranked second in 2017 after 1981, whereas it ranked third or fourth in Rottweil, Hechingen, Köln, Augsburg or Hannover mostly located in western and northern Germany (Fig. 2). Remarkably, it was unprecedented in Bern (202 GDD) and far higher than in any of the other 153 years, when the GDD was always below 120. The second highest GDD reached in Bern at the time of the last frost $\leq-4^{\circ} \mathrm{C}$ happened in 1873 on April $14^{\text {th }}$ with only 109 
GDD, far lower than the value of 202 GDD reached in 2017 (Fig. 2), but with temperatures recorded as low as $-7.3^{\circ} \mathrm{C}$. The same analysis for the threshold of $\leq-2^{\circ} \mathrm{C}$ generated similar results, with the frost event of 2017 being unprecedented in terms of GDD accumulated at 12 out of the 35 stations, all located in Switzerland and southern Germany. It was less exceptional at the other stations, especially in northern and eastern Germany (Fig. S1).

Across all 16 stations where temperatures dropped below $-4^{\circ} \mathrm{C}$ during the April 2017 damaging frost, the last event $\leq-4{ }^{\circ} \mathrm{C}$ occurred 33 days later in 2017 than the average 1981-2010 ( $94^{\text {th }}$ percentile, Fig. 3A). Since 1864,9 other years have shown later $\leq-4$ ${ }^{\circ} \mathrm{C}$ occurrences than 2017, with a deviation up to +45 days in 1873 (Fig. 3A).

Similarly, across the 51 study stations, the last frost event $\leq-2{ }^{\circ} \mathrm{C}$ occurred 23 days later in 2017 than the average $1981-2010$ ( $89^{\text {th }}$ percentile), but 15 other years showed later occurrences than 2017 , with a deviation up to +55 days for the exceptionally late frost that occurred in 1867 (May 25 ${ }^{\text {th }}$ ) (Fig. 3B). In contrast, considering temperatures prior to the frost event, our analysis shows that the April damaging frost 2017 below $4^{\circ} \mathrm{C}$ was very exceptional as it occurred after a much higher accumulated GDD than on all other years, with a deviation from the mean period 1981-2010 of +140 GDD (Fig. 3C). For values below $\leq-2^{\circ} \mathrm{C}$, the April damaging frost 2017 was also exceptional (averaged deviation of GDD +145 ), apart from the 1867 event, when a deviation from the mean period 1981-2010 of +260 GDD was reached at the time of the last frost event (Fig. 3D).

\subsection{Last spring frost, spring phenology index and GDD trends since 1864}

The GDD deviation accumulated across stations from $1^{\text {st }}$ January to April $19^{\text {th }}$, i.e. just before the occurrence of the April 2017 damaging frost, was the sixth highest value since 1864 (+70 GDD from the mean 1981-2010, Fig. 4A). The two highest values accumulated at that time of the year were reached in 1961 and 2007 with +98 and +112 GDD respectively (Fig. 4A). Since 1864, it has increased on average by $3.8 \pm 0.8$ degree.days.decade ${ }^{-1}$, and this trend has been highly accentuated after 1970, $\sim 16.8 \pm 4.7$ degree.days.decade ${ }^{-1}$ (Fig. 4A). Consistently, the Swiss spring phenology index, which reflects the time of vegetation development in spring compared to the long-time average from 1981-2010 across nearly 80 stations in Switzerland, has considerably advanced since 1970 (Fig. 4B). The GDD accumulated from $1^{\text {st }}$ January to April $19^{\text {th }}$ in the Swiss stations highly correlates with the Swiss spring phenology index $\left(\mathrm{R}^{2}=0.83\right.$, Fig. $\left.4 \mathrm{C}\right)$ demonstrating the robustness of the GDD as a proxy for plant spring phenology. Hence, the lowest values of the Swiss spring phenology index are found for years having the highest GDD deviation values, as in 1961, 2007, 2011, 2014 and 2017 (Fig. 4A \& 4B).

The last spring frost $\leq-4^{\circ} \mathrm{C}$ and $\leq-2^{\circ} \mathrm{C}$ has also progressively advanced since 1864 , with a trend of $-1.3 \pm 0.3$ and $-1.2 \pm 0.2$ days.decade ${ }^{-1}$, respectively, i.e. of about 20 days over the whole study period (Fig. 5A). For the $\leq-2^{\circ} \mathrm{C}$ threshold, the latest frost on record occurred in 1867 (Fig. 5A), with the temperature dropping to $-2.8^{\circ} \mathrm{C}$ in Bern on May $25^{\text {th }}$. Interestingly, the GDD accumulated at the date of last frosts, as a proxy for the risk of frost damage to plants, has not significantly decreased or increased 
during the period, remaining unchanged for both thresholds values $\left(\leq-4^{\circ} \mathrm{C}\right.$ and $\leq-2^{\circ} \mathrm{C}$ ), although with a high variability from year to year (Fig. $5 \mathrm{~B}$ ).

\section{Discussion}

Our results show that the April 2017 damaging frost was unprecedented in relation to the accumulated GDD at the time of the frost event for several stations where temperature dropped below $-4^{\circ} \mathrm{C}$, with no similar event being recorded since the beginning of temperature records in Switzerland and south of Germany, i.e. as far back as 1864 . For example, in Bern the temperature reached $-4.1^{\circ} \mathrm{C}$ during the late spring frost of 2017 at a time when more than 200 GDD had accumulated since January $1^{\text {st }}$, while on average such events had occurred at only 16.5 GDD since 1864 . Although the 2017 frost was quite late, it was not unprecedented in terms of calendar dates, as similar freezing temperatures have occurred up to a month later on previous years. However, climate warming has clearly accelerated the accumulation of daily mean temperatures above $5^{\circ} \mathrm{C}$ in early spring, triggering earlier vegetation onset. However, in spite of earlier plant phenology in spring, our results suggest that the risk of frost damage to perennial plants has remained unchanged over the last decades in these regions at lowland elevations due to the concurrent advance of potentially damaging frosts.

\subsection{Most vulnerable regions to the risk of frost damage in $\mathbf{2 0 1 7}$}

The April 2017 damaging frost was described by the media as the 'frost of the century' in Switzerland, where the economic losses were very high, particularly for vineyard and orchard owners. Our results confirm this statement, at least for the stations located in Switzerland with more than hundred years of climatic data available. For instance, the April frost 2017 was unprecedented in terms of heat accumulation in Bern, Altdorf and Zurich and ranked second or third in Schaffhausen, Luzern and Basel / Binningen. Although the 2017 frost occurred throughout Switzerland and Germany, there was a clear latitudinal gradient, with higher GDD values reached at the time of the frost event 2017 at southern stations, mostly located in Switzerland and in the south of Germany. This put the vegetation growing in these regions at higher risk of frost damage. A recent study using the long-term series of phenological observations in Switzerland showed that cherry trees require on average 147 GDD to flower and apple trees 219 GDD, whereas 185 GDD are necessary for European beech to leaf-out (Vitasse et al., 2018a). Our results show that these different thresholds had been largely exceeded at the time of the April 2017 frost event in most of the lowland regions in Switzerland and to a lesser extent in Germany (Tables S1 \& S2), explaining the important damage that was observed both for crops and natural vegetation (https://www.munichre.com/topics-online/en/2018/01/springfrost).

\subsection{Frost risk for vegetation has remained unchanged since 1864 despite earlier phenology}


The impact of climate warming is clearly visible in the values of GDD accumulated from $1^{\text {st }}$ January to April $19^{\text {th }}$ as they have increased by approximately 4 degree days per decade since 1864 and by approximately 17 degree days per decade since 1970 . Higher values for GDD in spring and a longer growing season, as a consequence of climate warming, has been reported at larger scale in Europe, potentially increasing yields for agriculture at higher latitudes where water stress is limited (Linderholm et al., 2008; Trnka et al., 2011; Wypych et al., 2017a; Wypych et al., 2017b). The positive effect of earlier phenology on agriculture yield will likely predominate in these regions, providing that the risk of frost exposure does not increase, as found here and in previous studies (Chmielewski et al., 2018; Trnka et al., 2011; Vitasse et al., 2018a). However, results may differ for natural vegetation at higher elevations or higher latitudes where spring phenology has advanced more than at lower elevations (Gusewell et al., 2017; Post et al., 2018; Vandvik et al., 2018; Vitasse et al., 2018b), possibly due to an acceleration of warming in spring in these regions and/or to increasing chilling causing earlier dormancy break (Vandvik et al., 2018; Vitasse et al., 2018b). At lower elevations, phenological response to warming has slowed down in Europe in recent decades, presumably because of chilling and/or photoperiod limitations that may reduce the risk of premature vegetation development during late winter after warm spells (Fu et al., 2015; Vitasse et al., 2018b).

Because of climate warming, farmers, fruit growers and forest managers are being encouraged to use plant varieties or species better adapted to current and future warmer and drier climates (FAO, 2007; Lindner et al., 2010). However, new summeradapted varieties/species may exhibit lower spring thermal requirements, which may lead to precocious growth, while there is still a stochastic risk of late spring frost, as exemplified in 2017. Active frost protection methods, such as aspersion irrigation, warming or air mixing techniques can be efficient but require expensive infrastructure. In Switzerland, the 2017 frost event stimulated the authorities to allocate funding for the installation of more equipment for aspersion, which appeared to be the most efficient method to protect crops against frost. Our analysis reveals that the 2017 frost event was nevertheless a true outlier in terms of risk of frost damage to plants and was not part of an increasing trend of frost exposure due to climate warming. This is in agreement with a recent study that has shown no change in the risk of frost damage to fruit and forest trees in Switzerland below 800m since 1975 using long-term series of both temperatures and phenological observations (Vitasse et al., 2018a). The challenge today is to determine which crop varieties could be more profitable under future warmer conditions in relation to their spring phenology requirements and their resistance to drought and heat waves.

\subsection{Limitations of the study}

This study covered a broad latitudinal gradient and thereby a high degree of phenological variation but was restricted to two countries only. Our analyses showed that the April 2017 frost event was only exceptional towards the south and west of Germany and in Switzerland but similar impacts are likely to have occurred in nearby 
regions at similar latitudes and elevations, such as the vineyards of Alsace in northeastern France (Bernadette and Bouchard-Aerts, 2017) or western Austria and northern Italy. In these regions important damages were also reported in crops by the local press.

Although GDD may not be the best proxy for predicting the phenology of some perennial temperate species, in particular the ones which are strongly regulated by photoperiod such as European beech (Vitasse and Basler, 2013), it has proved to provide rather good estimates of the vegetation onset for numerous other forest tree species and perennial crops (Sacks and Kucharik, 2011; Vitasse et al., 2011). Similarly, the temperature base above which temperature is assumed to promote spring plant development, here fixed at $5^{\circ} \mathrm{C}$ for computing the GDD, may differ among species or crop varieties (Akyüz and Ransom, 2015) and a linear accumulation of temperature above a threshold may also not accurately reflect how bud meristems respond to spring temperature, which could instead follow a sigmoidal response to temperature (Chuine, 2000; Hänninen, 2016). In spite of these limitations and of the acknowledged influence of chilling temperature exposition during winter dormancy (Coville, 1920), the high correlation obtained here between the Swiss spring phenology index and the GDD accumulated over late winter and early spring across all the Swiss stations demonstrates that the GDD still represents a powerful proxy for plant spring phenology. Overall, over the past decades, the Swiss and German climatic conditions likely provided sufficient chilling exposure to fully break bud winter dormancy (i.e. leading to a minimal amount of heat required to bud break). However, exceptionally warm winters as observed in 2007 or as expected in the coming decades in lowland regions may dramatically increase the heat requirement to budburst and therefore decrease the reliability of the GDD as proxy for spring phenology in the future (Asse et al., 2018; Vitasse et al., 2018b). Finally, here we assessed the risk of frost exposure using the GDD reached until the last frost below $2^{\circ} \mathrm{C}$ but earlier damaging frost may have occurred, especially under more severe frost intensity. However, we assumed that last spring frosts below $-2^{\circ} \mathrm{C}$ are the most critical for plants because, at this date, plant development is more advanced than during previous frost events and hence plant cold hardiness should also be lower (Vitasse et al., 2014; Vitra et al., 2017).

\section{Conclusions}

Our results show that the April 2017 damaging frost was unprecedented since instrumented records began in 1864 in terms of the risk and exposure of the vegetation in several regions of Switzerland and south Germany. Prior to the April 2017 frost event, warm spring temperatures had resulted in more advanced vegetation development than in any other year when a late frost event below $-4^{\circ} \mathrm{C}$ occurred. However, despite substantial warming and earlier vegetation growth, our study suggests that the frost risk for vegetation has remained unchanged since 1864 at lower elevations in Switzerland and Germany. The April 2017 damaging frost was not part of a trend towards increasing frost exposure to plants as, due to climate warming, the 
yearly last frost events also occurred progressively earlier, leveling off a potential higher risk of frost damage due to earlier spring phenology. Passive measures against frost, such as planting adapted varieties, remain the cheapest way to avoid frost damage. But a challenging issue for fruit growers today is to assess whether promoting new varieties adapted to warmer and drier climates during summer time (generally with an earlier spring phenology), could be more profitable in future decades.

\section{Author Attribution}

YV and MR designed the research and interpreted the results together. YV analyzed the data and elaborated the figures. YV wrote most of the text after MR wrote the first draft. 


\section{Figures}

Fig. 1
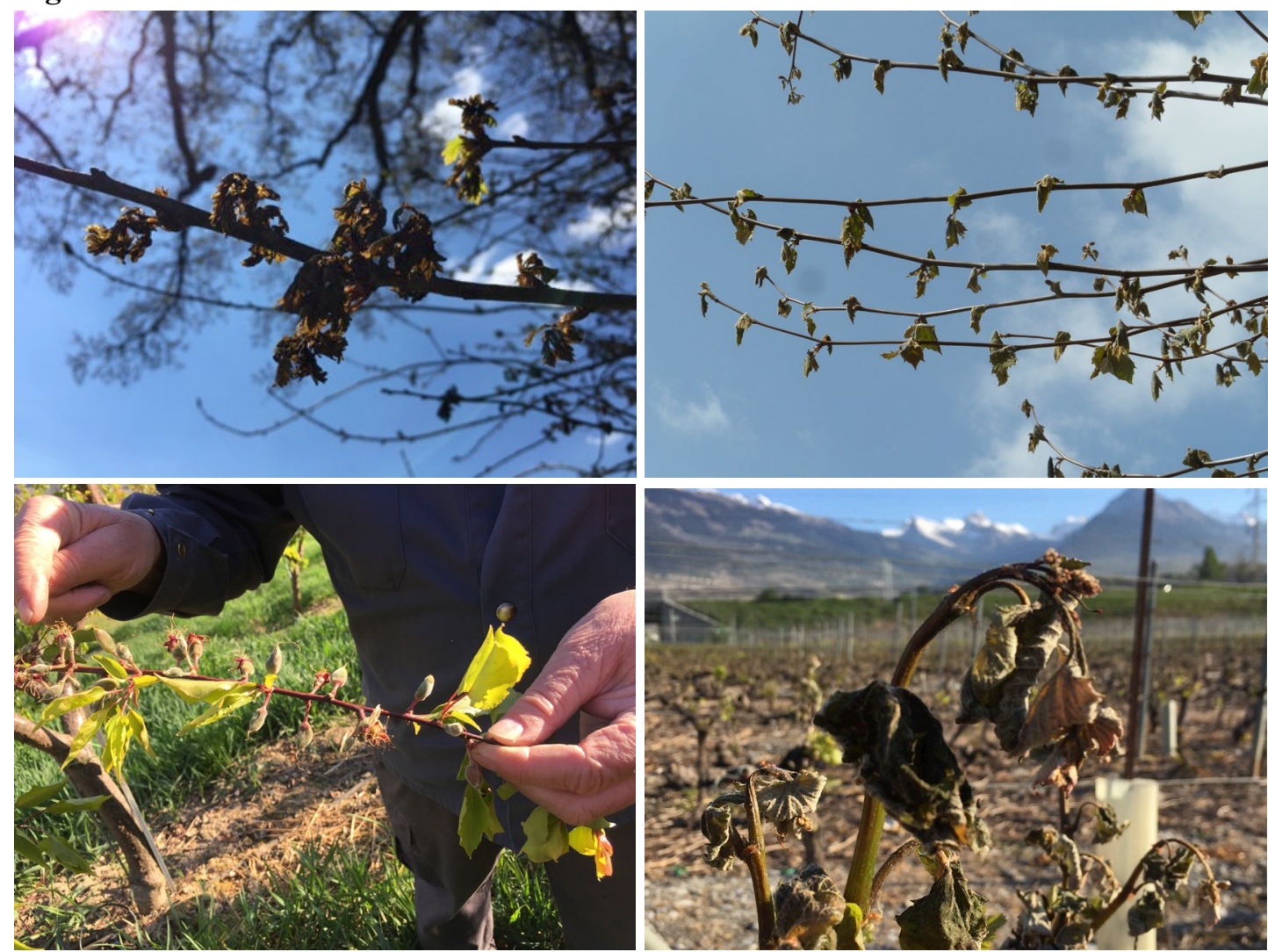

Fig. 1 Frost injuries observed on various plants following the April 2017 damaging frost event (20-29 April 2017). Top left panel: oak trees in Delémont, Switzerland, approx. 430m asl on 29 April 2017 (C) Y. Vitasse; Top right panel: street trees (plane trees) in Delémont, Switzerland, approx. 430m asl, on 30 April 2017 (C) Y. Vitasse; Bottom left panel: apricot trees in Conthey, Switzerland, approx. 500 masl on 21 April 2017 (C) M. Rebetez; Bottom right panel: vineyard in Conthey, Switzerland, approx. 500m asl, on 21 April 2017 (C) M. Rebetez. 
Fig. 2

A

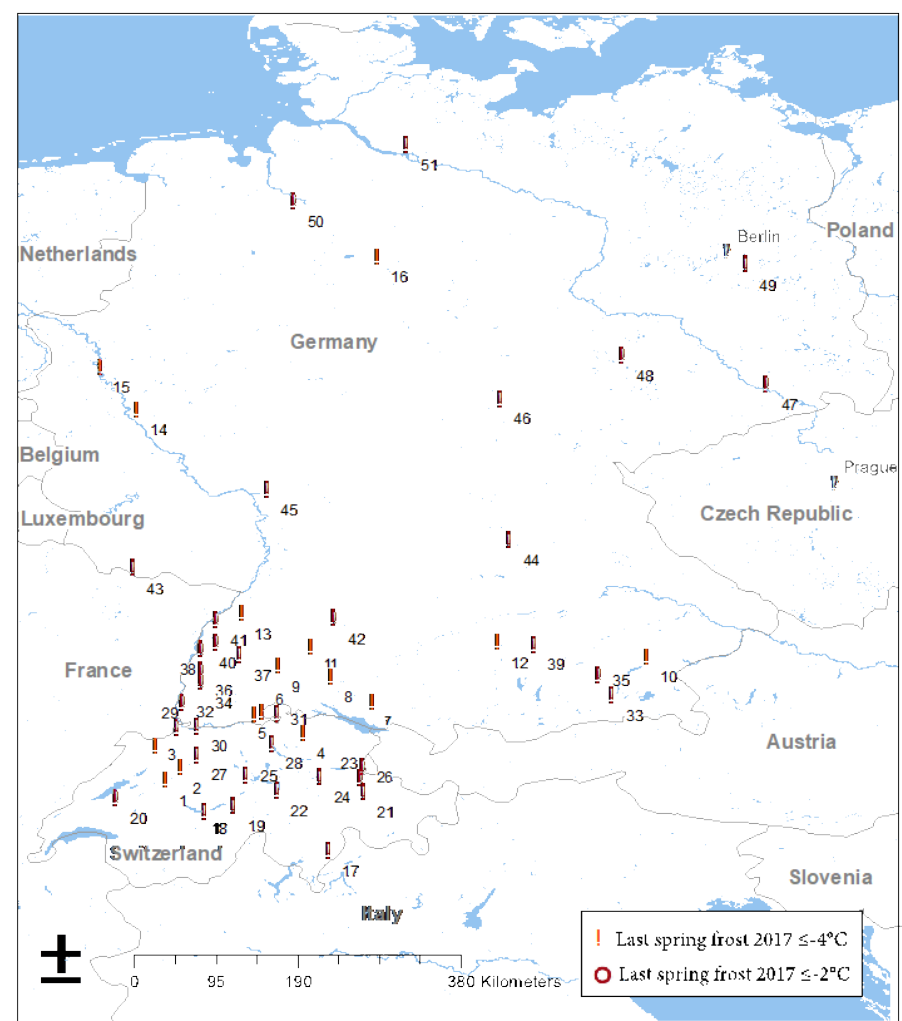

B

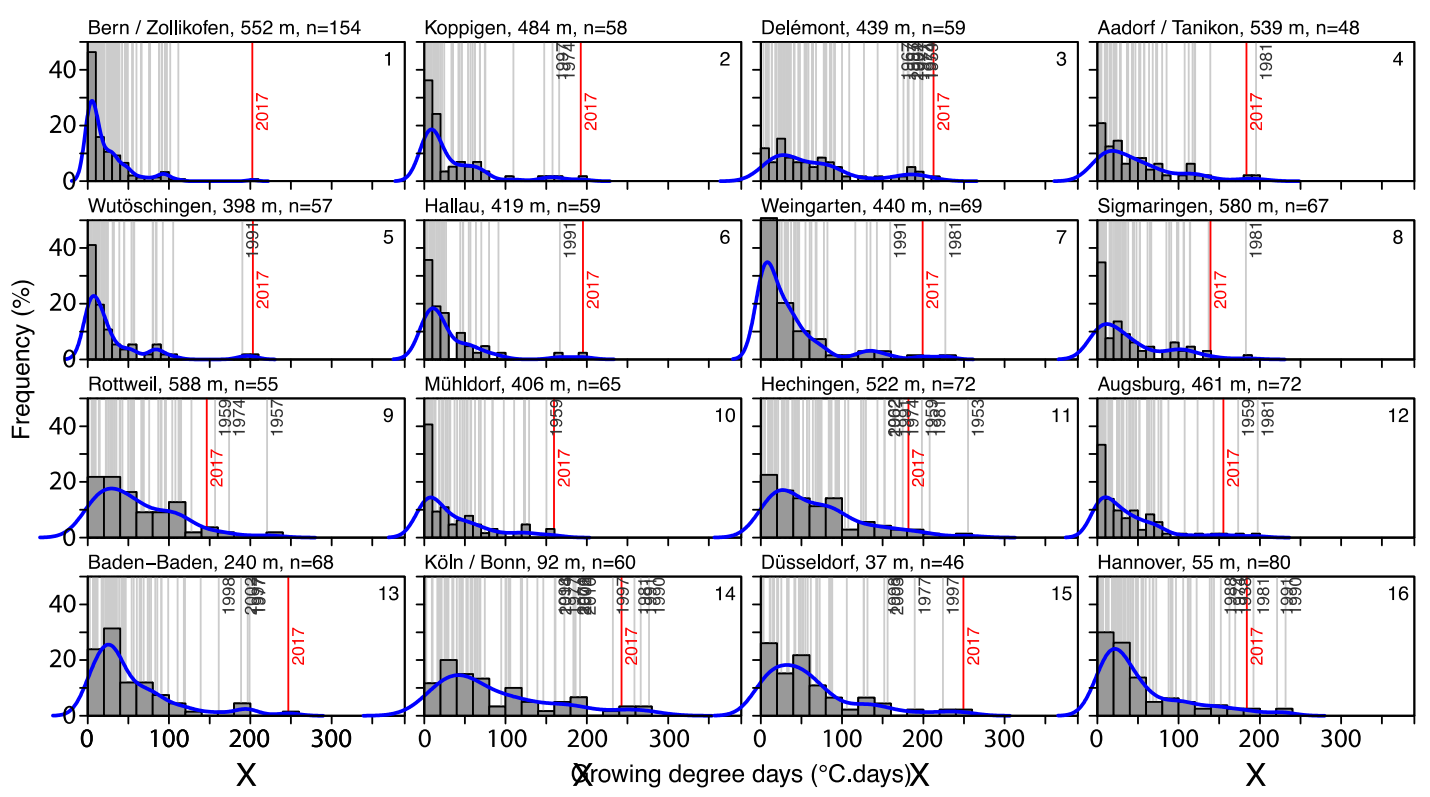

. Stations where temperature was recorded $\leq-4{ }^{\circ} \mathrm{C}(1-16)$ and $\leq-2^{\circ} \mathrm{C}(17-$

51) during the April 2017 damaging frost are represented with filled and open circles respectively. B, Accumulated growing degree days (GDD) from 1 January to the date of the last frost occurrence $\leq-4^{\circ} \mathrm{C}$ for stations where temperature was recorded $\leq-4^{\circ} \mathrm{C}$ during the April 2017 damaging frost, i.e. on 20-29 April ( $\mathrm{n}=16$, filled circles on the map). 2017 is shown in red. Lists of all stations are also provided in the supplementary material (Tables S1 \& S2). 
$1 \quad$ Fig. 3

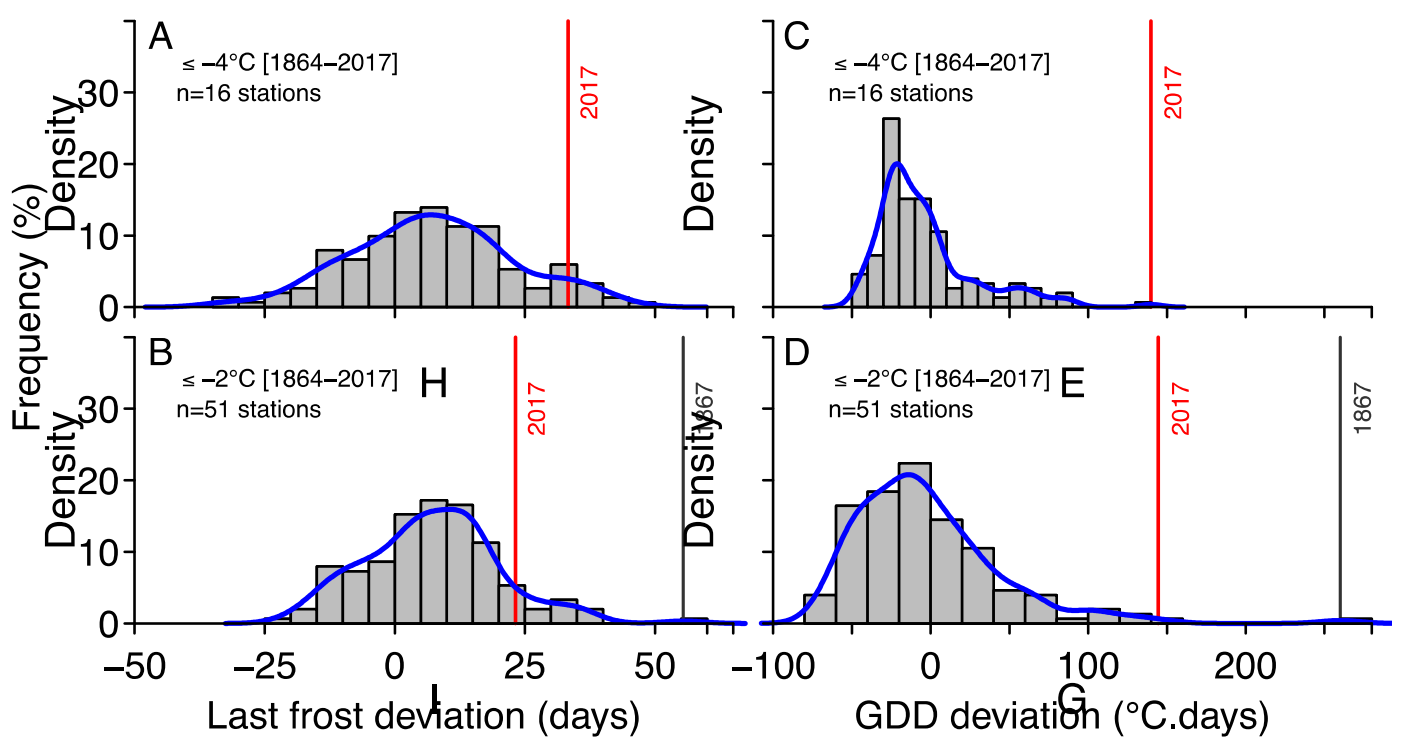

2

15 16 7

Fig. 3 Relative frequency of occurrence date of the last frost deviation $\leq-4{ }^{\circ} \mathrm{C}$ (A) or $\leq-2^{\circ} \mathrm{C}$ (B) and of the growing degree days (GDD) deviation accumulated from 1 January to the last frost $\leq-4^{\circ} \mathrm{C}(\mathrm{C})$ or $\leq-2^{\circ} \mathrm{C}(\mathrm{D})$ in all stations below $600 \mathrm{~m}$ asl. with at least 40 years of available temperature records and where temperature was recorded $\leq-4{ }^{\circ} \mathrm{C}(\mathrm{n}=16)$ or $\leq-2^{\circ} \mathrm{C}$ $(\mathrm{n}=51)$ during the April 2017 damaging frost (20-29 April). GDD and frost deviations

were computed from the mean 1981-2010 values for each station and year. Kernel density curves were fitted to the distribution. 2017 is shown in red and 1867, when another 10 exceptionally late frost event $\leq-2^{\circ} \mathrm{C}$ occurred, is shown in grey. Note that the available 1 data years vary between stations before 1976, starting from 1864 for the earliest one (see Fig. S2). 

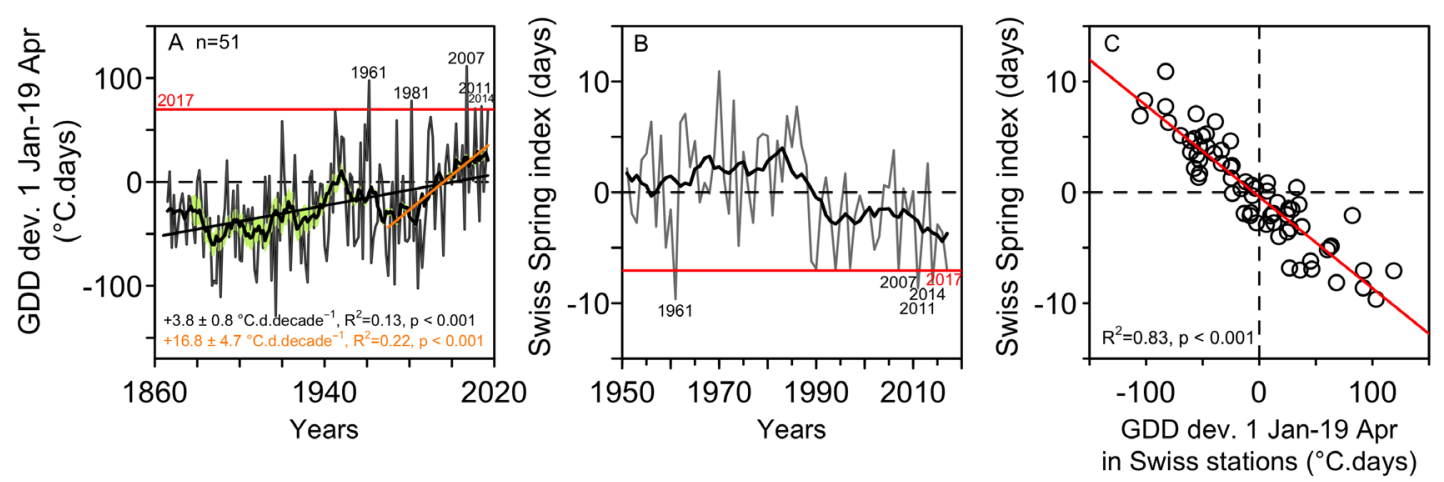

19

20 Fig. 4 Growing degree days (GDD) deviation, Swiss spring phenology index and their

21 correlation. A, Growing degree days (GDD) deviation from January $1^{\text {st }}$ to April $19^{\text {th }}$ at all

22 stations below $600 \mathrm{~m}$ asl. where temperature dropped below $-2^{\circ} \mathrm{C}$ on $20-29$ April 2017 and

23 with more than 40 years of data in Switzerland and Germany $(n=51)$. For each year and

24 station, GDD deviations were computed from the mean value 1981-2010 of the given

25 station and were then averaged across stations. 2017 is shown in red and years with higher

26 GDD deviation values than 2017 are indicated. Eleven-years moving averages are

27 represented (black thick line) and SD across stations are also shown (green surrounding

28 area). Note that the available data years vary between stations before 1976, starting from

291864 for the earliest one (see Fig. S2) and that the SD is absent before 1881 as only one

30 station has temperature records available from 1864 to 1880 (see Fig. S2). B, Swiss spring

31 phenology index, representing the time of vegetation development in the spring compared

32 to the long-time average from 1981-2010 across 80 stations (see details in the Method

33 section). Eleven-years moving averages are represented (black thick line). C, correlation

34 between the GDD deviation computed within the Swiss stations only $(n=19)$ and the

35 Spring phenology index. Linear regression is shown. 

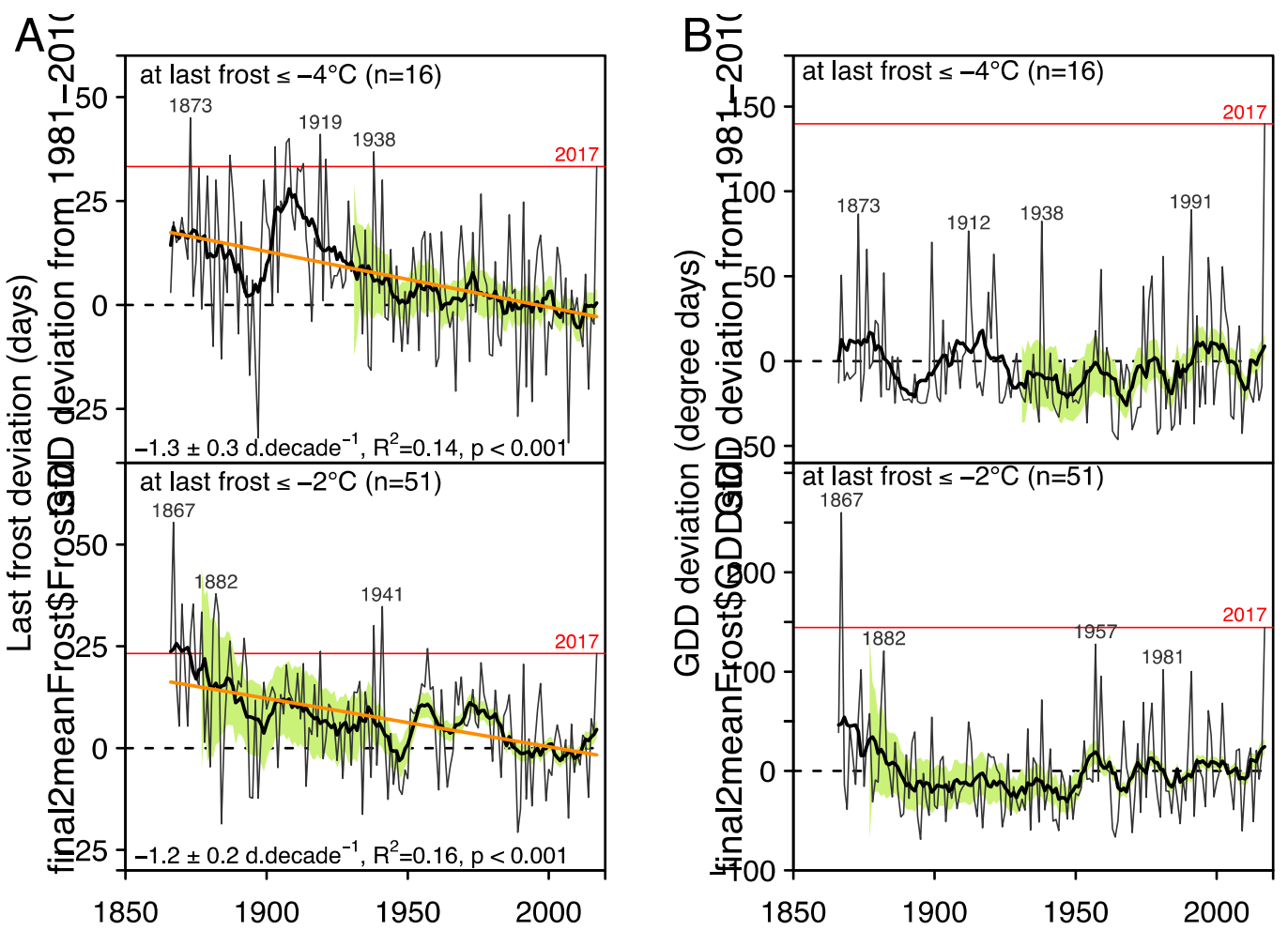

at the time of the last frost event $\left(\leq-4^{\circ} \mathrm{C}\right.$ and $\left.\leq-2^{\circ} \mathrm{C}\right)$ from the mean $1981-2010$ at all stations below $600 \mathrm{~m}$ asl. with more than 40 years of temperature data where temperature was recorded below $-4^{\circ} \mathrm{C}(\mathrm{n}=16)$ and below $-2^{\circ} \mathrm{C}(\mathrm{n}=51)$ on $20-29$ April 2017. Elevenyears moving averages are represented (black thick line) and SD across stations are also shown (green surrounding area). 2017 is shown in red and the years with the highest values are indicated in grey. Note that the SD is absent before 1881 and 1936 respectively when analyzing stations where temperature has dropped below $-2^{\circ} \mathrm{C}$ or below $-4^{\circ} \mathrm{C}$ during the April 2017 frost, as temperature records are only available for a single station before these years (see Fig. S2). 